\title{
Placemaking, livability and public spaces. Achieving sustainability through happy places
}

\author{
Marichela Sepe \\ IRISS-CNR, University of Naples Federico II, Italy \\ marisepe@unina.it
}

\begin{abstract}
Livability of places is set by many factors which are in turn influenced by a variety of elements - both tangible and intangible - concerning the area in question and its surroundings. One of these factors is constituted by urban happiness, which, together with the term sustainability meant in its wide meaning, constitutes a key concept in placemaking. In this respect, a new attention to urban happiness has been given but often in terms of theoretical sense or from an observational point of view. Aim of this study is to present the Happy place mapping, a method of analysis specifically devoted to the identification of factors that influence the perception of happiness from the urban point of view. To illustrate the method, the emblematic HafenCity case study carried out in Hamburg is showed. A long process of urban regeneration is interesting this area and the new public spaces are changing the identity of the city, making it more livable and agreeable both for locals and visitors. The discussion on questions related to methods that concern intangible aspects and on Happy place mapping conclude the paper.
\end{abstract}

Keywords: placemaking; urban happiness; sustainable public spaces

To cite this article:

Sepe M. (2017). Placemaking, livability and public spaces. Achieving sustainability through happy places. The Journal of Public Space, 2(4), 63-76. DOI: I0.5204/jps.v2i4. 14 I

This article has been peer-reviewed and accepted for publication in The Journal of Public Space.

Please see the Editorial Policies under the 'About' section of the journal website for further information. 


\section{Introduction}

Livability of places is set by many factors, which are in turn influenced by a variety of tangible and intangible elements - such as good quality design and materials, place identity, accessibility and so on - concerning the area in question and its surrounding (AAVV, 2017; Appleyard, 198I; Kyttä et Al, 20I5; Burns, 2005).

Urban happiness (Carmona et Al., 20I0; PPS, 200I; Evans et Al, 20II) is one of these factors and contemporaneously one of its synonymous that, together with the term sustainability meant in its wide meaning, constitutes a key concept in placemaking, namely, in the "art of making places for people" (Sepe, 2017).

Urban environments are increasingly designed to be distinctive, trying to create memorable sensory experiences and give happiness for the people who use them.

Through the analysis of places, a more detailed and qualitative interpretation of the city is carried out. This is not circumscribed to its aesthetic essence, nor even to its physical geometry (Gehl, 20I0; Kyttä et Al., 20I5; Lynch, 1960; Madanipour, 2003).

The functional and symbolic interpretations of the elements of a place are the fundamental factors for understanding its meaning. And "as society changes, so does signification (McCay, 20 I7; Montgomery, 1998, 20I3). Meanings attached to the built environment become modified as social values evolve in response to changing patterns of socio-economic organization and lifestyles" (Porteous, 1977).

Nowadays, a new attention to the urban happiness has been given but often in terms of theoretical sense or from an observational point of view. Indeed, the definition of urban happiness is strongly interwoven with social, environmental, economic, philosophical studies and, according with new crisis and consequent transformation of lifestyles, needs and habits, the definition is in continuous change (Taylor et Al., 1998; Wang et Al., 2016; Whyte, 1980; Zelinka et Al., 200I)

On the other hand, as mentioned before, the definition looks to be similar to that used for defining well-being, quality of life, and sustainability (PPS, 200I; Relph, 1976; Saunders, 2017).

Accordingly, urban happiness could be defined as a character which gives to the place a positive perception in people who live it and which induces them to spend long time there and/or to live there again the same experience (Gehl, 20I0; Sepe, 2017; Zidansek, 2007).

Starting from these premises, aim of this paper is to present the original Happy place mapping, carried out in the framework of the IRISS - CNR National Research Council research project titled: "The design of the contemporary urban landscape: place identity, urban happiness, livability and health", coordinated by the author.

The Happy place mapping aims at identifying urban happiness and the factors which make places happy from the users point of view. As will be illustrated in the following sections, the method consists in surveys, observations and questionnaires. A series of case studies have been carried out in Europe, USA and China. The case study carried out in the HafenCity area of Hamburg (Germany), which is interested by a process of whole urban regeneration, will be illustrated. The HafenCity urban regeneration process is creating new challenges and a definition of place identity which makes this case study particularly relevant for the topic of the paper. The paper is organized as follows: section 2 describes the method; section 3 illustrates the case study in detail, according with the different phases; section 4 shows the discussion and, finally, section 5 draws the conclusion. 


\section{Achieving urban happiness: the method}

"Happy place mapping" consists of five phases (table I). In all the surveys ad hoc database are created to collect the information suitably.

The first phase consists in the selection and definition of the study area. It is necessary to go to the site in question and, through one or more inspections, decide whether to confirm the delimitation decided beforehand or modify it.

The second phase entails observing the characteristics of the place through three surveys which concern activities, perceptions and elements which contribute to the feeling of happiness.

In the first survey, it is necessary to observe the types of people (locals, visitors, professionals, etc.) and activities (leisure, passing by, work, etc.). These activities are analyzed from a quantitative point of view, considering two main factors. Firstly, the number of people making use of the space is measured (low, medium, high).

Secondly, it is necessary to observe the frequency with which the activity is repeated or implemented and at what pace, namely if that activity is carried out at a rapid, slow or moderate pace. In addition, the influence of the activity on liveability (low, medium, high) has to be assessed.

The second survey consists in the identification of singular visual, auditory, tactile, olfactory, taste perceptions, as well as mixed perceptions, such as chaos, serenity, disorder, joy, harmony, disorientation, deriving from the sum of one or more perceptions. Then it is necessary to observe their quantity expressed as a low, medium or high percentage as well as their quality expressed as pleasant, non influential or annoying. The third survey of this phase consists in the observation of elements which contribute to the sensation of happiness such as constructed and natural elements, transportation modes, equipment and services (furniture, wireless, etc). Finally, from the comparison of these data, a first finding about the degree of happiness is obtained.

The third phase consists in an open questionnaire to be administered to the users of the site, aimed at identifying factors and elements which make people who live in that place happy or sad.

Questions may include the following and can be modified in accordance with the characteristics of the place.

I. Does this place give you a feeling of happiness or sadness?

2. What are the elements that make you happy or sad here?

3. What are the facilities that make this place good or bad?

4. What kind of activities (sporting, recreational, professional, etc.) do you do in this place? How often?

5. Does the presence of many or few people improve the pleasantness or unpleasantness of the place?

6. What could be done in order to improve this place?

7. Have you lived in a "happy place" in this city or elsewhere?

8. Do you think that the weather conditions can influence the perception of this place?

The fourth phase is that of the analysis of the cartography in order to understand the elements that compose the place in terms of the type of urban layout, the historical and architectural elements, the natural environment (sea, hills, etc.), and other public spaces in the surrounding area. 
The fifth phase involves the construction of the map of happiness with the identification of spaces and features that give the perception of happiness to the people who use that place.

The final analysis map will be the result of all the information collected with the different survey operations, analyses and observations (table I).

\begin{tabular}{|c|c|c|c|}
\hline Phase & Objective & Actions & Product \\
\hline First & $\begin{array}{l}\text { Definition of the } \\
\text { area }\end{array}$ & Visit on site & $\begin{array}{l}\text { Map with the } \\
\text { definition of the } \\
\text { borders }\end{array}$ \\
\hline Second & $\begin{array}{l}\text { Observation of } \\
\text { characteristics of } \\
\text { the place }\end{array}$ & $\begin{array}{l}\text { Surveys of: } \\
\text {-Activities } \\
\text { - Perceptions } \\
\text {-Elements }\end{array}$ & $\begin{array}{l}\text { Dabase of survey } \\
\text { results }\end{array}$ \\
\hline Third & $\begin{array}{l}\text { Questionnaire to } \\
\text { users of analyzed } \\
\text { place }\end{array}$ & $\begin{array}{l}\text { Identification of } \\
\text { elements which } \\
\text { make people who } \\
\text { use that place } \\
\text { happy }\end{array}$ & $\begin{array}{l}\text { Dabase of survey } \\
\text { results }\end{array}$ \\
\hline Fourth & $\begin{array}{l}\text { Analysis of } \\
\text { cartography }\end{array}$ & $\begin{array}{l}\text { Urban analysis of } \\
\text { the place }\end{array}$ & Urban analysis map \\
\hline Fifth & $\begin{array}{l}\text { Identification of } \\
\text { urban happiness }\end{array}$ & $\begin{array}{l}\text { Overlapping and } \\
\text { identification of } \\
\text { places, activities } \\
\text { and elements that } \\
\text { make people happy }\end{array}$ & $\begin{array}{l}\text { Map of urban } \\
\text { happiness }\end{array}$ \\
\hline
\end{tabular}

Table I. Happy Place Mapping scheme

\section{Happy public space}

\section{I. Experiments}

The experiments of the Happy place mapping were carried out in public spaces and areas different by types, geographic locations and dimensions. The case studies that have been carried out have both the aim to verify the method and identify what are the factors that influence happiness of places.

In particular squares, pedestrian and semi-pedestrian streets, urban parks and waterfronts, cultural districts were selected, particularly representative for the respective cities. These include: Hankou River in Wuhan, Lungomare Caracciolo in Naples, Bordeaux Waterfront in Bordeaux, The Bund in Shanghai with respect to the waterfronts; 798 Art District in Beijing; Nanluoguxiang in Beijing; Museums Quartier in Vienna as regards the cultural districts; Millenium Park in Chicago, Citygarden in Saint Louis (Missouri), and Promenade du Paillon in Nice, and HafenCity public spaces in Hamburg, in regards to parks; the Ramblas in Barcelona, the Graben in Vienna, in regards to thoroughfares; the Stadtlounge in St Gallen, the Place des Voges in Paris, the Piazza del Campo in Siena and Piazza Trevi in Rome, in regards to squares. These areas are emblematic for the respective cities, because in many cases these are both symbolic and representative of the whole city. 


\subsection{HafenCity case study}

The case study that will be illustrated concerns the HafenCity area in Hamburg, Germany, a 155 hectares area,interested by a wide operation of urban regeneration which started in 1998 (fig.l). Surveys, observation and questionnaires were carried out during a year and in different periods, both during weekdays and weekends, during daytime and afternoon hours.

The first phase consists in the choice and definition of the study area. Three site inspections were carried out on the whole study area and in the surroundings to identify the sites of interest for the experiment aims. Places which were chosen for the experiments concern the HafenCity public spaces that in their totality give continuity to the area. Namely the boundaries, which were identified regard: Hubenerstrasse on Southern part and Am Sandtorkai on North, including Grasbrookhafen, Sandtorhafen on western part and Am Sandtopark on East.

\subsection{The characteristics of the place}

The second phase is characterized by the observation of the characteristics of the place. Surveys which were carried out concern the activities which are effectuated in the spaces and relative modalities, relative perceptions and elements which contribute in different ways to the happiness of the place.

With respect to the first survey, the typology of people (locals, visitors, professionals, etc..) and activities (passing by, work, break, etc..) were observed. These activities are measured from the quantitative point of view, namely measuring how the specific activity is present in that place and influences its livability and frequency.

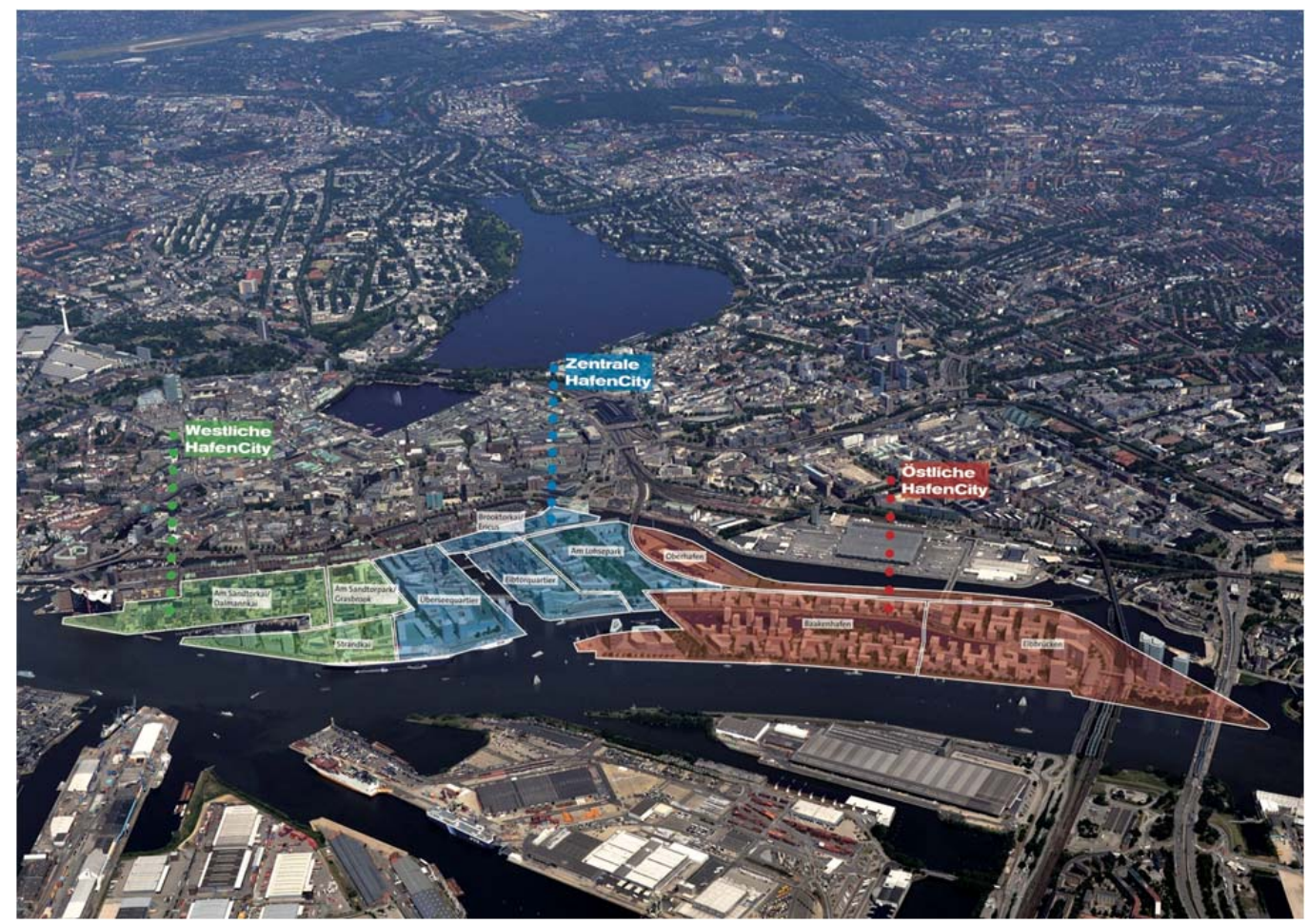

Fig. I HafenCity Quarters (Source: http://www.hafencity.com/de/presseportal-der-hafencity.html; Originator: Michael Korol / HafenCity Hamburg GmbH; Illustration: Michael Korol, Source: HafenCity Hamburg $\mathrm{GmbH}$ ) 
In order to illustrate the activities, the place was divided in 6 stretches (figs I, 2a-d):

I. Grasbrook

2. Marco Polo Terraces

3. Dalmannkai Promenade

4. Vasco de Gama

5. Magellan Terraces

6. Überseeboulevard

Grasbrook playground, Marco Polo Terraces, Vasco de Gama Platz and Magellan Terraces are connected each others trough the Dalmannkai Promenade and Überseeboulevard (Figures 2 a-d).
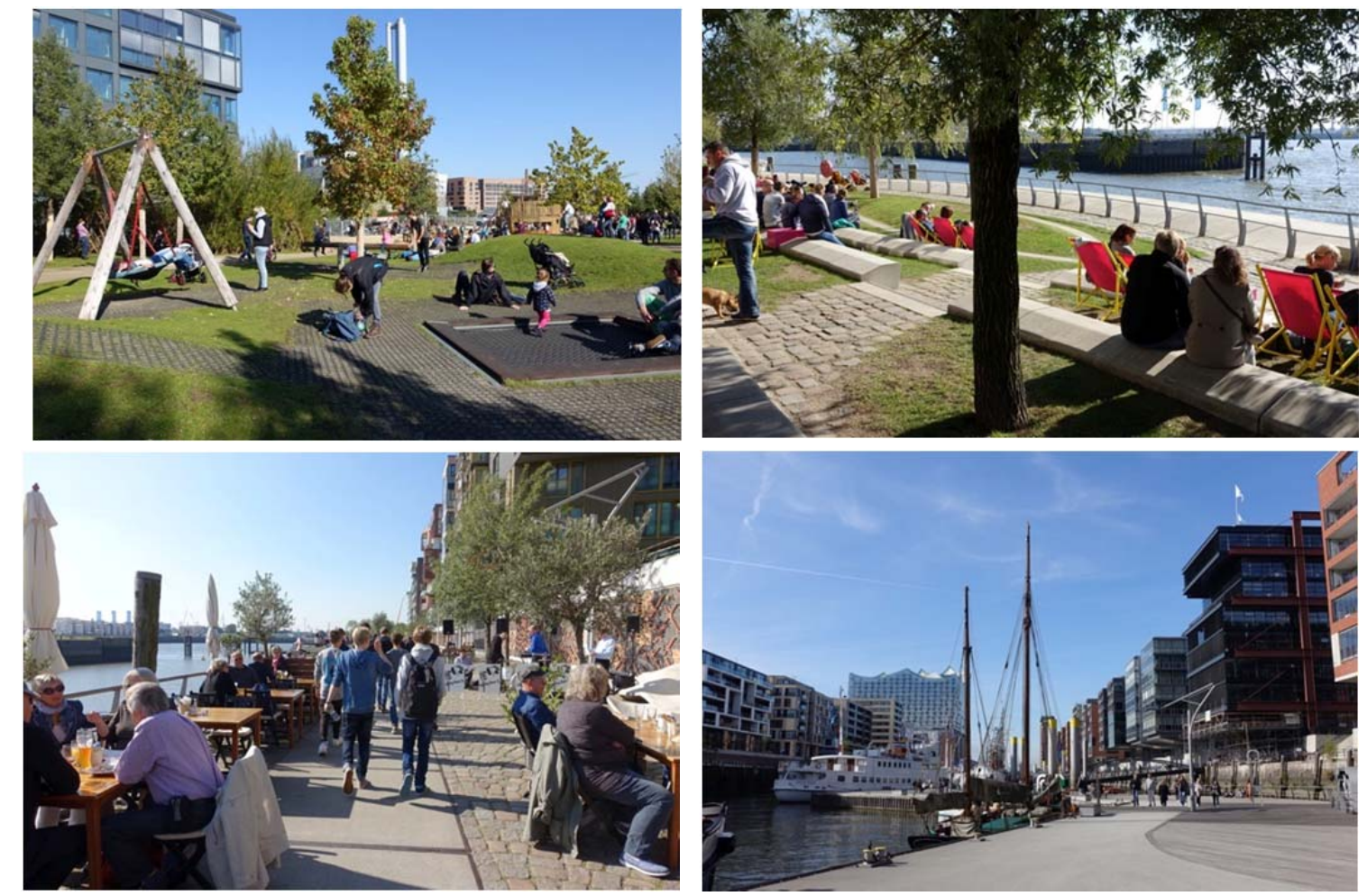

Figure 2. HafenCity public space (photos by the author): (a) Grasbrook; (b) Vasco de Gama Platz; (c) Dalmannkai Promenade; (d) Magellan Terraces.

Surveys, which started in Grasbrook and ended in Überseeboulevard, were carried out in the daily and afternoon hours both on weekdays and weekends. An average of results obtained in the different surveys is illustrated in the following section. When particular differences during a specific day or hours were observed, this information will be reported.

In regards to activities, which are present in the Grasbrook playground, the main ones concern: the playing, pic-nic, break, educational activity, socialization, passer-by. The playing activity is carried out in frequent manner by children of different ages also of nursery or primary class - in the morning hours - or with adults in different hours of morning and afternoon, in both cases frequently.

For the children of primary school, the leisure activity is often connected to the educational ones, devoted to illustrate the new HafenCity area and its meaning in relation 
to the reconstruction of the maritime identity trough the games which are present in the Grasbrook playground.

Next area is constituted by the Marco Polo Terraces, where activities which are present include: observation, break, socialization, lunch break, passing-by and cycling. The activity which is mainly present is the break carried out by people of ages between about 20 and 50 years both during the daily and afternoon hours in frequent manner. To this activity that of the lunch or coffee break is equally present and the socialization often happens within groups of 2-3 people. The activity of passer-by and cycling is also present and is carried out in all the HafenCity public spaces.

Public spaces continue with the Dalmannkai Promenade where the Vasco de Gama Platz is situated as well. In the Dalmannkai Promenade the most frequent activities include: the passer-by, cycling and taking a brake in one of the different place for sitting, from where it is possible to admire the sea from many points of view. The medium age of people who carry out this activity is between 20 and 60 years and the typology is mainly constituted by locals, residents (mainly workers of the area), and tourists Furthermore, there is the presence of some bar, shops with souvenir and restaurants which increase the activity of taking a break, even though in private places. On the Vasco de Gama Platz, the most present activity is that of break, carried out in frequent manner on the part of the square overlooking the sea which is furnished with deck chairs.

Continuing to walk Dalmankai Promenade the Magellan Terraces is reached. The activities that are mainly present include the break, cycling, walking and observing. These activities are mainly carried out by people aging between 20 and 50 years. Break takes place both on the benches and on the terraced steps. From there, the break is improved by the observation which take place in different part of the surrounding space. Furthermore, the urban landscape is enriched by the close museum of music from a side and, from the other, by the old sailing ships - visitable - and the different buildings which create a very diversified urban landscape.

Finally the Überseeboulevard is reached, where the prevalent activity is walking followed by the break in the different bar and restaurants of the area. Both the activities are very frequent and carried out by people of all the age, locals, residents and tourists.

The pace with which these activities are carried out is generally moderate and slow, offering a very agreeable perception of that place.

The second survey of single and mixed perceptions has been carried out. With regards to the single perceptions, these are all involved but the taste one - in particular in the Grasbrook playground. Perceptions which are more felt and are all agreeable include: the sound one, given by the voices of people who live this place, and by the water of the games; the tactile, given by the different material - sand, water, meadow and wood which are used for the ground of the park; that visual, given by the scenic games with which the park is built; the smell, given by the smell of the natural material used for the features of the park, and by the sea situated not so far as well. In the Marco Polo Terraces, Dalmannkai Promenade, Vasco de Gama Platz and Magellan Terraces, the single perceptions which are felt regard: the visual ones concerning the sea and surrounding constructions, including from different points of view that of the Elbphilharmonie and of the old sailing ships on the Magellan Terraces; the acoustic ones, concerning the sounds of voices and foot steps of people, low and agreeable, and in some moments, the sound of the passing ships; the tactile ones, concerning the different pavements of the walks and sittings - wood, asphalt, concrete and meadow -; the smell one, due to the smell of the sea, and - in particular close to the Dalmannkai Promenade, the smell of coffee and food. 
Finally, observing the Überseeboulevard, perceptions include the acoustic one due to the sounds of means of transports and building sites - the area is still in development - and the taste one, due to the food of many restaurants and cafes of the area.

In regards to the mixed perceptions, during the inspections, the most frequent which were identified are those of cheerfulness, joy and serenity. The feeling of cheerfulness is perceived mainly at the Gransbrook Park, due to the children's games built with natural material. The feeling of joy and serenity can be relieved in all the public spaces, as testified by both the low or moderate pace with which these activities are carried out and the high frequency. The only part where the chaos is perceived is that of Überseeboulevard area, due to the works of construction sites which are still in development.

Then the third survey is that of element which contribute or less to the perception of happiness. The elements of the area which contribute to that perception include: the presence of possibilities of large public sittings in different points: from those which are built in concrete, to the deckchairs, to the stairs, creating multiple choices of activities which vary from the observation of the place to the lie down for sunbathing (during the warm months), to the making the lunch or coffee break. The sittings are located in a well organized and designed paths posed on different levels which allow both walking and cycling. The presence on the Magellanean Terraces of the historical sailing ships contribute at creating a welcoming atmosphere, recalling to the ancient maritime memory of the place. The historical memory is also due to the Speicherstadt industrial warehouses which were recovered, contributing to the beauty of the place. Old and contemporary given by the new architectures among them the Herzog-De Meuron Elbphilarmonie create an image of continuity with the whole city of Hamburg and then of cultural sustainability as well. The perception of continuity is also given by the old and new bridges which connect HafenCity with the rest of the city without solution of continuity.

\subsubsection{The Questionnaire}

The phase 4 has concerned: the questionnaire on site to the users of place devoted to comprehend the elements which make people happy or sad in the living of that place and the research of the same information trough the online research of guest reviews.

With regards to the on site questionnaire, this was administered to about 100 people, both local and tourists, in English. Questions are posedt mainly to people while taking a break on the benches or on the lawn in the different stretches of the HafenCity. All the people who are interviewed have answered to the questions, even though have dedicated different time for answering.

To the question "Does this place give you a feeling of happiness or sadness", the totality of people both locals and tourists answered of happiness, even though with a different meaning, depending on the different stretches of the area. The term happiness has been used mainly for Grasbrook park, while for the other spaces the terms which were used include joy, serenity, livability and sustainability, recalling agreeable sensations perceived in HafenCity. As regards the second question, "What are the elements that make you happy or sad here", answers regard different elements. Locals who were interviewed were both people who work on the area $(70 \%)$ and people who work and live in elsewhere $(30 \%)$. For the locals, the majority ( $80 \%)$ of people answered the possibility of enjoying the sea, public spaces, bar and restaurants and then the facility of connection with the center of Hamburg. In regards to tourists, about $80 \%$ answered that the elements concern the new architectures, the strolling among the old sailing ships, the boats which pass from there, bar, the presence of many places for sitting. The $20 \%$ of both has answered in a more 
generic manner, affirming that this is well maintained and organized. To the question "What are the facilities that make this place good or bad", people, locals have mainly (70\%) answered the playground, the deckchairs and the other sittings, the presence of the University with many outdoor public spaces. The majority of tourists $(80 \%)$ has also added the little modern sculptures, the sailing ships, and the HafenCity info Pavillon with information concerning the different phases of urban transformation and the model of the whole area. The remaining part of interviewees both local and tourists answered the public and private ships for the tour of HafenCity by the sea.

To the question "What kind of activities (sporting, recreational, professional, etc.) do you do in this place? How often", answers were different but consistent with the possibility of activities which the place offers. Locals who live there have answered that they go to HafenCity to work and that they use public spaces in the lunch break. The remaining locals have answered that they go to HafenCity to walk, to go to the playground - in particular adults with children and class of scholars - to go to the bar or to make a break, with a week frequency or more often with public means of transport which arrive in the centre. Tourists have all answered that HafenCity is a new and very beautiful area of Hamburg which visit in one-two days, making a break, strolling in the public spaces and eating or drinking in the cafeterias or restaurants.

To the question, "Does the presence of many or few people improve the pleasantness or unpleasantness of the place?" The $90 \%$ of people answered that the presence of a medium quantity of people increases the pleasantness of the place, giving an atmosphere of vitality to the area. The different functions which are present in the area offer a frequency by people of different age, provenience and professions. In regards to the question "What could be done in order to improve this place", the answer given by locals ( $80 \%)$ was mainly nothing. Some of them (10\%) have affirmed the quicker completion of the work sites that intrude the livability of the place, while another little part (10\%) affirmed that more green space should be inserted. Tourists have mainly answered $(85 \%)$ that they would not change anything. The remaining part have given answers very different among them, including the organization of more artistic events (10\%), the insertion of more areas of interest for the elderly (5\%), the insertion of areas for repairing people from rain in the winter periods.

To the question "Have you lived in a "happy place" in this city or elsewhere", answers concerned many places given the variety of people who have been interviewed. Locals (70\%) answered the Rathaus Platz of Hamburg which represents a sort of symbolic place of the city, others $(30 \%)$ answered the square - always in Hamburg - with the swans and ducks to be admired. Tourists have given the more diverse answers - including the London docks, the Barcelona waterfront, the Boston waterfront, etc..-, referred to their city of belonging and to the connection of those with the sea, where existent. Finally, to the question "Do you think that the weather conditions can influence the perception of this place", answers were different. Many areas are used the whole year, because here there are many professionals, students and residents. In the period of cold and rains the perception of the place change for many people $(85 \%)$ due to the difficulty to stay for long time outdoor. In that period spaces which are more used are mainly the private ones.

As regard the research of reviews through web sites, the first data which emerge is the high presence of the HafenCity on the web: e.g. through the google research engine 2.200.000 results have been found. The web site which reports the major number of reviews is tripadvisor with about 600 reviews focused on HafenCity. As regards people 
who have answered the comment, these are mainly European and Central American of age included between 25 and 60 years old. Comments are always positive. Aspects which are evidenced regard the operation of urban regeneration which is for them successful, the beauty of buildings, public spaces, the presence of and restaurants and the cleaning of the area. In the comments - all positive -, there are also evidenced the aspects connected to the relation with the sea, the old sailing ships and the boats for the visit of the area from the sea.

\subsubsection{The traditional analysis}

As regards the traditional analysis (phase 4), an important aspect which is emerged is that history has played a fundamental role in the waterfront regeneration. Although only a partial reconversion of the harbour warehouses is carried out, the project is restoring the maritime vocation of the historical city and is strictly connected with the city (Sepe, 201320I4) (figg. I,3).

The HafenCity project is recovering the maritime identity of the historical city and will be strictly connected with the city. Hamburg is one of the major European ports and the Germany's main port. Indeed, the town joined the Hanseatic League in the first half of the thirteenth century, and Hamburg played a key role in the League. Following this period, the South American states became important commercial partners of Hamburg's shipping companies and merchants in the first half of the nineteenth century. This caused a great increasing in the harbour's cargo volume to require the construction of the city's first modern port basin, Sandtorhafen. The port developed into the current HafenCity in the course of the nineteenth century. The other port basins which were built include: Grasbrookhafen, Magdeburger Hafen, Brooktorhafen, and Baakenhafen, whose low marshes were gradually raised to $4-5 \mathrm{~m}$ above sea level to protect the port structures from flooding. Great Fires and the World Wars, caused many destructions to the port. Only after 1945, reconstruction begin, and, concomitantly, a significant growth in freight traffic.

The history is present in different places of the Hafencity area. Also due to the brick-built impressive facade - which is remained almost visually unchanged-, the Speicherstadt warehouse plays an important role acting as an entrance and a joining element: the warehouse is listed as a historic monument and is designed to be acknowledged as a Unesco World Heritage Site in 2014. New functions were established in the Speicherstadt, including: museums, traditional goods storage, multimedia agencies and creative business, as a sort of bridge between old and renovated image. Another important element in the recovering the place identity is the old harbour basins with its buildings which represent a place of attraction for both locals and visitors. The historical buildings which were retained became the landmarks of HafenCity. The Speicherstadt, the Elbphilharmonie Concert Hall, the International Maritime Museum, and the old Port Authority building are only an example of the new project intervention (Sepe, 20I320I4).

The project is subdivided into eight main areas, including: Am Sandtorkai, Dalmannkai quarter, Grasbrook, Strandkai, Uberseequartier, Elbtorquartier, Am Lohsepark. Brooktorkai and Elbbruken. An elaborate articulation of private and public spaces has been designed, many of them already completed (figs I,3). The building of HafenCity will increase the surface of the original Medieval City Center city by $40 \%$. The new area - 155 hectares of the Medieval city's overall area - is constituted by two thirds of land and one third of water and it is expected that I2,000 of the city's residents will have moved to 
HafenCity in the next ten years, while stimulating the creation of 20,000 new jobs. The operation of regeneration is coordinated by a private company, the HafenCity Hamburg $\mathrm{GmbH}$, which is owned by the Free Hanseatic City of Hamburg, and which manages relations between the public and the private sector.

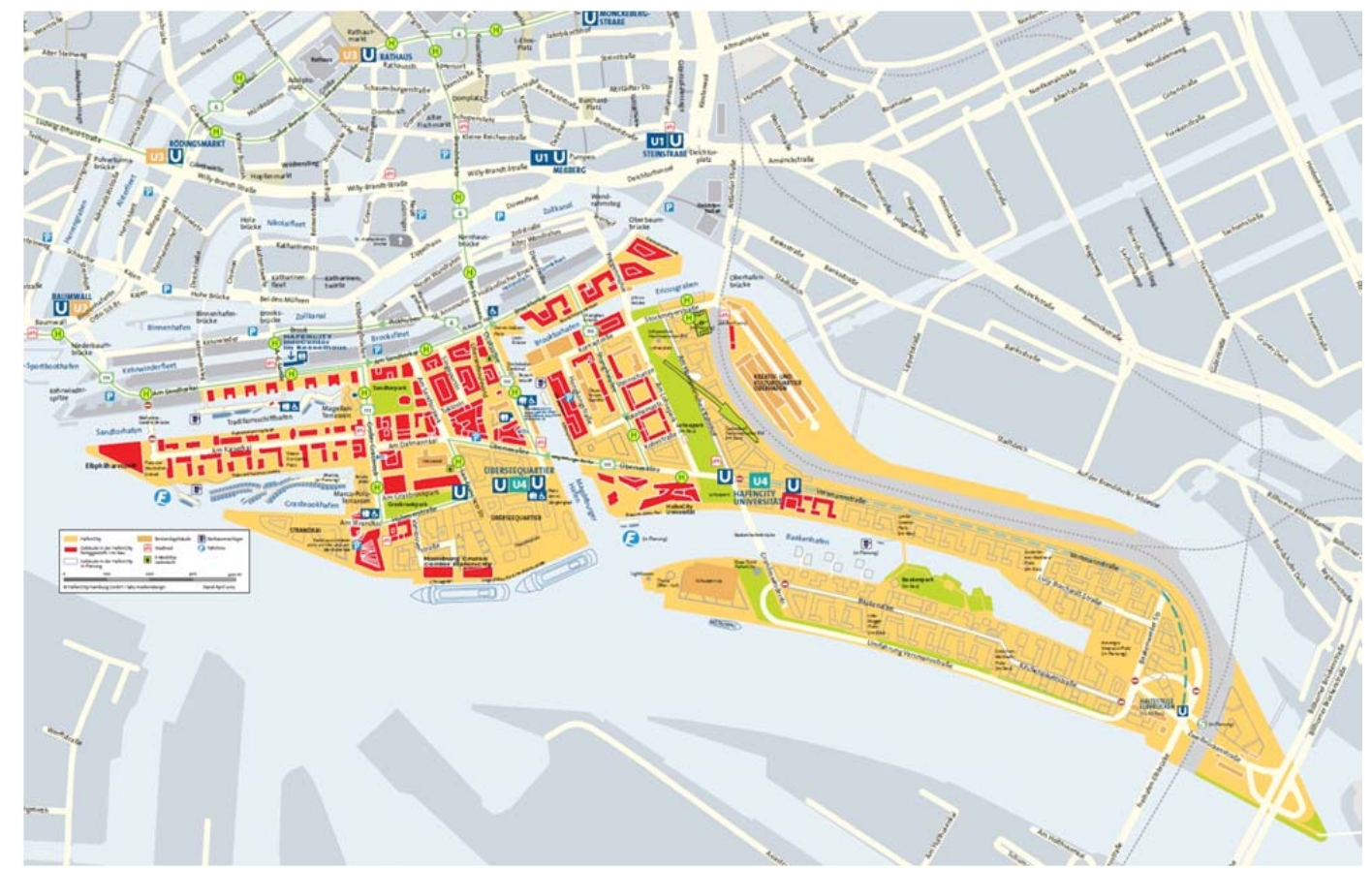

Figure 3. HafenCity area (source http://www.hafencity.com/de/presseportal-der-hafencity.html; Originator: lab3 mediendesign / HafenCity Hamburg GmbH; Picture credits: illustration: lab3 mediendesign, Source: HafenCity Hamburg Gmb

Finally, the last part of the traditional analisys has regarded the mobility project in development. In Hafencity the motorized individual transport will be reduced from the 47 per cent of Hamburg to the 20. The HafenCity area lies less than a kilometre away from Hamburg City Hall and the city centre, it is thus easily reachable even on foot. Its services are readily available to the citizens of the rest of Hamburg as well as HafenCity's own residents. Seventy percent of foot and cycling paths run from lanes which are separated by motorized traffic. The public transport, including ecological buses and river taxis and the new U4 subway stations, connects HafenCity with the rest of the city and contributes to the ecological, economic and socially sustainable integration of the new district. The new $10 \mathrm{~km}$ of waterfront along the Elbe are in this way reconnecting the city to its river.

\subsubsection{The happiness of the place}

The fifth phase of the method concerns the identification of elements that contribute to the happiness of that place. HafenCity is an area that has many elements of interest. This study is referred to the public spaces which constitute an important part of this because favors its liveability.

Due to its nearness with the historical centre of Hamburg, but also thanks to the wild operation of participation which has been carried out from the beginning of the project of regeneration, the area is very known to the inhabitants of the city and to the tourists and then very lived. The presence of public spaces with many possibility of sittings has 
determined that both professionals who work there than locals coming from other areas of Hamburg use this place with frequency and low or moderate pace.

The presence of tradition, given by both the Speicherstadt warehouses and the historical sailing boats and innovation, given the new architectures, offer an atmosphere of both memory and contemporaneity which like to people who visit the place. The presence of an InfoPavilion and a maritime museum on the Magellan Terraces inform people on the history of the place and the on-going project of regeneration, offering a further element of participation.

Another aspect of success is the presence of pedestrian and cycle paths integrated also in the design: different levels, many visual perceptions and urban landscapes in perspective, an articulated design which create variety in who live it.

The realization of a playground for children -also used by students for educational trips is a further aspect of success of the area, together with the presence of the new HafenCity University which creates a continuous use of the place. The sea is lived in its multiple "shape": as a background of architecture, as a landscape scene to be observed from different points of view, and as a place to be lived and admired, thanks to the possibility to take both public transport boats and touristic ships for different kinds of tours. The presence of bar and restaurants offer the possibility of extending the stop in a pleasant way. Serenity, joy, happiness and surprise are the most solicited sensations in that place.

\section{Discussion}

The Happy Place Mapping method which was used is aimed at allowing the identification of factors which influence happiness of the place. Through different surveys, analysis and questionnaire the elements which contribute to the sensation of happiness were identified and concern both tangible and intangible aspects.

Studies on the intangible aspects which are connected to the city are many and involve many disciplines, such as sociology, environmental psychology, anthropology and so on. The method which is presented in this paper is an evolution of the PlaceMaker method (Sepe, 2013, 2015) - created by the author as well - which is devoted to the identification of elements which constitutes the place identity and intervention for its enhancements. Identity of places, while in its elusiveness, has constituted by very tangible elements such as the architecture of buildings, the urban morphology, etc. In line with this concept, urban happiness can be - only at the first stage of analysis - considered influenced by perceptions. Also in this case, perceptions and intangible aspects are strongly connected to architectures, public spaces, natural environment and hence with its sustainability. In regards to the proposed method, during the surveys (phase 2) it has been observed that some improvements should be done with respect to the kinds of database which are used. These have to be more flexible in order to allow the variety of situation which occur in the places. Another observation regards the questionnaire, this is an important tool to understand factors which influence happiness. On the other part, sometimes answers are too generic or not strictly related to urban facts. What is important in these cases, is to reformulate questions in order to have suitable answers which are useful for the case study aims.

A last observation concern the last phase, in which the factors influencing happiness emerge as a overlapping of all the elements collected during the previous phases. Happiness is a fluid concept, above all in the intangible aspects. So the method has to be 
easily updatable in order to allow the collection of new information and the creation of new results. As regards a computer science tool which support this operations should be useful.

\section{Conclusion}

The paper has presented the method of urban analysis Happy place mapping and a case study carried out in the HafenCity area of Hamburg, in course of completion.

The HafenCity project intends to recreate the maritime identity of the historical city and be strictly connected with the city. The area is emblematic as a case study because this is a new area which is creating a new urban identity to the whole city, improving its livability and degree of satisfaction in both locals and visitors, and hence its sustainability.

This case study, as mentioned before, is part of a series of case studied carried out in area with different geographical localization and dimension. Each case was useful to comprehend if it is possible to identify common factors - related to urban design capable to give happiness in people who live it. The HafenCity case has strongly contributed in that sense and the results of all cases are leading at a definition of the Principles for the livability and happiness of public space.

The surveys and questionnaire have demonstrated that tangible aspects - such as variety of functions and accessibility - regard the HafenCity project of public spaces. Indeed, the new public spaces, for their variety and articulation, offer multiple possibilities to be lived from different subjects with different needs and preferences. Furthermore, the area is very close to the historical centre of the city and easily reachable with different means of transport, creating facility of access and crossing.

The intangible aspects are related both to the beauty of the place in itself, due to the presence of the sea and landscape, but also to historical memory given by the Speicherstadt warehouses and the sailing ships visible, from the different points of views of the pedestrian paths and public spaces.

Another aspect which is fundamental for the happiness and livability of these public spaces is the presence of a wide variety of sittings with both sea and landscape view where it is possible to take a break or look around contributing to a sensation of serenity.

On the other hand, an important aspect to be considered is constituted by the clime and weather as well, which in the winter period is rigid. The frequency of public spaces in these periods is more limited for questions connected to the weather, although the presence of public buildings and private societies offers life in the place during the whole year.

Finally, the results of the case study demonstrates that the public spaces of HafenCity can be considered sites where manifestation of happiness and livability is relieved, affirming itself as emblematic place in this sense.

\section{References}

AAVV (2017). Health and Urban Design. Urban Design Group Journal, 142, 12-39. Appleyard, D. (198I). Livable Streets. Berkeley: University of California Press.

Ballas, D. (2013). What makes a 'happy city'? Cities 32, 539-550.

Burns, G. W. (2005). Naturally happy, naturally healthy: The role of natural environment in wellbeing. In F. A. Huppert, N. Baylis, and B. Keverne eds. The science of well-being. New York: Oxford University Press. 
Burton, L. (20I5). Mental well-being. In H. Barton, S. Thompson, S. Burgess, and M. Grant (Eds) The Routledge Handbook for Health and Well-Being. London: Routledge.

Crappsley, R. (2017). Designing Streets for Good Health: Now and in the Future, Urban Design Group Journal, 143, I0-II.

Carmona, M., Heath, T., Oc, T., and Tiesdell, S. (2010). Public places-Urban spaces. Oxford: Architectural Press.

Evans, B., McDonald, F., and Rudlin, D. (20I I). Urban Identity. Learning from Place. London, New York: Routledge.

Florida, R., Mellander C., and Rentfrow, P.J. (20I3). The happiness of Cities, Regional Studies, 47, 613-627.

Friedmann, J. (2010). Place and Place-Making in Cities: A Global Perspective, Planning Theory \& Practice, II (2) I49-165.

Gehl, J. (2010). Cities For people. Washington: Island Press.

Kyttä, M. et al. (20I5). Urban happiness: context-sensitive study of the social sustainability of urban settings, Environment and Planning B, 43(I), 34-57.

Lynch, K. (1960). The Image of the city. Cambridge: MIT Press.

Madanipour, A. (2003). Public and Private Spaces of the City. London, New York: Routledge.

McCay, L. (2017). Designing Mental Health into Cities, Urban Design Group Journal, 142, 25-27

Montgomery, J. (1998). Making a City: Urbanity, Vitality and urban Design, Journal of Urban Design, $3,93-116$.

Montgomery, C. (20I3). Happy City. London: Penguin.

Porteous, J. D. (1977). Environmental and behavior: planning and everyday urban life. Reading, Massachusetts: Addison-Wesley.

Project for Public Spaces (200I) How to Turn a Place Around: A Handbook for Creating Successful Public Spaces. Project for Public Places, New York City, NY.

Relph, E. (1976). Place and Placelessness. London: Pion.

Saunders, L. (20I7). Healthy Streets, Urban Design Group Journal, 142, 35-36.

Sepe, M. (2013). Planning and Place in the City. Mapping Place Identity, London, New York: Routledge.

Sepe, M. (20/3). Urban history and cultural resources in urban regeneration: a case of creative waterfront renewal, Planning perspective, 28 (4), 595-6I3.

Sepe, M. (20I4). Urban transformation, socio-economic regeneration and participation: Two cases of creative urban regeneration, International Journal of Urban Sustainable Development, 6 (I), 20-4I.

Sepe, M. (2015). Improving Sustainable Enhancement of Cultural Heritage: Smart Placemaking for Experiential Paths in Pompeii, International Journal of Sustainable Development and Planning, 10, (5) 7I3-733.

Sepe, M. (2017). The Role Of Public Space To Achieve Urban Happiness, International Journal of Sustainable Development and Planning, 2 (4) 724-733.

Taylor, A. F., Kuo, F. E., Sullivan, W. C. (1998). Growing up in the inner city: Green spaces as places to grow, Environmental Behavior 30 (I) 3-27.

Wang, D., and Shenjing, H. (eds.) (2016). Mobility, Sociability and Well-Being of Urban Living, Heidelberg: Springer.

Whyte, W.H. (1980) The social Life of small public space, Conservation Foundation: Washington DC, 1980.

Zelinka, A., and Brennan, D. (200I). Safescape, Creating Safer, More Livable Communities Though Planning and Design. Chicago: Planner Press APA.

Zidansek, A. (2007). Sustainable development and happiness in nations, Energy, 32, 89I-897. 